\title{
EDITORIAL
}

\section{What makes a medical leader? ${ }^{\dagger}$}

\author{
Dinesh Bhugra
}

\begin{abstract}
Dinesh Bhugra is Professor of Mental Health and Cultural Diversity at the Institute of Psychiatry, King's College London, and Honorary Consultant Psychiatrist at the

South London and Maudsley NHS Foundation Trust. He is current President of the Royal College of Psychiatrists. Correspondence Professor Dinesh Bhugra, Institute of Psychiatry (KCL), De Crespigny Park, London SE5 8AF, UK. Email: d.bhugra@iop.kcl.ac.uk
\end{abstract}

${ }^{\dagger}$ See pp. 162-170, this issue

\section{SUMMARY}

Medical leadership is important and must be a part of training. It requires qualities at three levels: the personal, the interpersonal (working with and through others) and the organisational (in political and cultural contexts). Some of the traits of good leadership can be taught and learnt, whereas others are inherent. The roles of individual leaders depend on the organisations in which they are involved. Different contexts require different leadership styles.

\section{DECLARATION OF INTEREST} None.

Medical leadership and its competencies have become buzzwords in the past few years. What is medical leadership? Why is it important and why should we take any interest in it? Equally, what is it not? Medical leadership is not about running teams, although that may be a part of it: it is much more than that. It is about an awareness of what lies ahead and how one can turn challenges and changes into opportunities for delivering better patient care. Garg et al (pp. 162-170, this issue) highlight some of the issues involved, particularly in the context of training and competencies. However, leadership goes beyond what can be taught and learnt: it also requires vision, passion, courage and horizon-scanning. Not everyone is a born leader and not everyone can be trained to be one. The challenge for the medical profession is to identify potential leaders and then to train and support them. Also, not everyone has a dream to become a leader. So steps must be taken to make the role of leadership an attractive one from a career perspective. Maintaining leadership skills will need additional resources which may not always be available in the current economic climate.

\section{Leadership in healthcare}

Doctors probably remain the most trusted professionals as far as the public is concerned but that trust has to be earned. Similarly, medical leadership needs to be clearly defined and earned. Good medical leaders are proactive in moulding the views of stakeholders to ensure that health services are fit for purpose. In this context, medical leadership is about achieving healthcare that is of excellent quality, is acceptable and accessible to all, and one that the leaders themselves would be proud to use. The vision that a leader holds and is able to convey requires the confidence to stand up against policies that may be wrong or inappropriate, and to fight or help to amend them.

\section{Roles and responsibilities}

The roles and responsibilities of leaders, medical or otherwise, vary according to the functions and structures of organisations they are leading. The roles of the medical leaders in a National Health Service (NHS) or private hospital or an organisation such as the Royal College of Psychiatrists are remarkably different. Although these leaders will have similar skills, in one organisation their focus may be on horizon-scanning, in another on communicating: nowhere in the Medical Leadership Competency Framework is this made clear (NHS Institute for Innovation and Improvement 2010).

Leaders exist only if there are followers. The reasons why people choose to follow one individual rather than another are many, but of primary importance is the leader's ability to communicate their vision and take people along with them.

In engaging with key stakeholders, whether they be service commissioners or policy makers, leaders must have not only self-confidence, but also the confidence of their followers. Having the vision to improve a service is as important as the ability to turn that vision into a focused strategy, to communicate it to others and convince them that it is the right way to go. These characteristics are very different. And how does one assess the competencies to ascertain vision in a leadership trainee?

Furthermore, it is important to recognise that, with changes in doctors' roles and NHS strategies, the emphasis on the different competencies of specialist core training will change too (Royal College of Psychiatrists 2010). Thus, for trainees and their mentors and educational supervisors, there must be enough flexibility in the system to allow account to be taken of an individual's leadership strengths and weaknesses and for leadership training to take these individual factors into account. There is always a danger in competency-based learning that training and assessments become tick-box exercises rather than proper examination of skills. 


\section{Levels of leadership}

Leadership requires qualities at three different levels: the personal, the interpersonal and the organisational.

The most important is the personal level, calling on the leader's personality and character. The personal qualities required are many. They include passion and commitment, confidence and practical wisdom, an ability to communicate clearly, curiosity and creativity with a sense of purpose, the skills to manage and cope with change, emotional intelligence and courage in believing that something needs to be done and doing the right thing. Some of these skills are also essential in good management. It is not unusual to find leaders who can both manage and lead - and managers who can both lead and manage.

At the second level, the leader needs skills in working with and through others. These include the ability to motivate and inspire, to empower and support, and to encourage and challenge others to ensure that they are able to deliver their best. By encouraging and enabling others, it is possible to develop the next generation of leaders. Some leaders are unable to do this, thereby creating a vacuum when they move on, making the organisation much more vulnerable to change. Again, some of these skills are part of the individual's inherent ability to trust and motivate people.

At the third level, the leader must be aware of existing and changing cultural and political contexts. They must be able to assess and analyse situations for themselves and for others. They must also be able to listen to and understand the analyses of experts. In this, the leader must have the ability to articulate their vision and convey the drive for clear and successful outcomes.

These personal skills and characteristics need to be identified and discussed across the medical profession.

\section{Cultural context and style of leadership}

As mentioned above, medical leaders must be aware of the culture of their organisation and the broader context within which it functions. Successful organisations are built upon the vision of the leader and their ability to take others with them. Being clear, open-minded, willing to learn and resourceful will enable the leader to achieve much more.

As highlighted by Garg et al, the Medical Leadership Competency Framework includes demonstrating personal qualities (self-awareness), working with others, managing and improving services, and setting directions (NHS Institute for
Innovation and Improvement 2010). Some of these skills can be learnt and others are inherent. The challenge is to determine which personality traits contribute to better leadership skills.

\section{Leadership style}

Theories of leadership offer a framework within which these skills can be developed. The impact and significance of leadership for any organisation is likely to be long term, and an organisation's functioning may need to be seen both separately and in the context of the leadership provided. The influence of leadership style can be substantial within the changing cultural, economic and political context of the organisation. Different styles of leadership work in different settings and one size does not fit all (for further discussion of the theories and practice of leadership see Nohria \& Khurana 2010).

\section{Conclusions}

Theory of leadership is helpful in providing a framework, but the skills required of a leader vary according to the function of an organisation and the leader's role within it. It is often asked whether leaders are born or made. The answer, of course, is a bit of both. In part, the personality traits and skills required to be a successful leader in healthcare can be learnt and developed, they can be instilled by example and by teaching, using attachments and placements.

Leadership training for psychiatric trainees must take into account both personal traits and training as psychiatrists. As clinicians we are trained to predict potential problems and course of illness, so as leaders we ought to be able to do much the same. As psychiatrists we should be aware of group dynamics and should therefore be best placed in delivering leadership. Medical leadership is crucial in the planning, delivery and development of services in a cost-effective, efficient and efficacious manner.

\section{References}

Garg S, van Niekerk J, Campbell M (2011) Medical leadership: competencies in action. Advances in Psychiatric Treatment 17: 162-170. NHS Institute for Innovation and Improvement, Academy of Medical Royal Colleges (2010) Medical Leadership Competency Framework: Enhancing Engagement In Medical Leadership (3rd edn). NHS Institute for Innovation and Improvement (http://www.institute.nhs.uk/images/ documents/Medical\%20Leadership\%20Competency\%20Framework\%20 3rd\%20ed.pdf).

Nohria N, Khurana R (2010) Handbook of Leadership Theory and Practice. Harvard Business Press.

Royal College of Psychiatrists (2010) A Competency Based Curriculum for Specialist Core Training in Psychiatry: Core Training in Psychiatry CT1-CT3. Royal College of Psychiatrists (http://www.rcpsych.ac.uk/pdf/ CORE\%20CURRICULUM\%200ctober\%202010.pdf). 